\title{
Metabolic surgery for type II diabetes: an update
}

\author{
Paolo Gentileschi ${ }^{1} \cdot$ Emanuela Bianciardi ${ }^{2} \cdot$ Domenico Benavoli $^{3} \cdot$ Michela Campanelli $^{1}$ [D
}

Received: 6 April 2021 / Accepted: 15 April 2021 / Published online: 18 May 2021

(c) The Author(s) 2021

\begin{abstract}
Bariatric operations have been documented in clinical trials to promote remission or dramatic improvement of Type II Diabetes Mellitus and related comorbidities. Herein we review randomized trials and meta-analyses published during the last 20 years on the results of bariatric/metabolic surgery in obese patients with type 2 diabetes with the aim of highlighting the scientific evidence available. Several studies and RCTs in the last 20 years have showed outstanding results of bariatric/ metabolic surgery on Type II diabetes and comorbidities in patients with either BMI $>35 \mathrm{~kg} / \mathrm{m}^{2}$ or BMI $<35 \mathrm{~kg} / \mathrm{m}^{2}$. They have established that bariatric procedures are superior to non-surgical interventions for inducing weight loss and amelioration of type 2 diabetes, even in patients with a BMI between 30 and $35 \mathrm{~kg} / \mathrm{m}^{2}$. The physiopatologic changes that improve glucose homeostasis after bariatric surgery remain unclear but glycemic control is improved after sleeve gastrectomy, duodenaljejunal bypass, Roux-en-Y gastric bypass, gastric banding, One Anastomosis Gastric Bypass, and biliopancreatic diversion. Nevertheless, it is suggested that the various gastrointestinal procedures may have different effects and mechanisms of action. Metabolic surgery will help integrate knowledge and multidisciplinary expertise to provide a combination of conservative and surgical treatments for Type II diabetes. These treatments must be considered as complementary options and not alternative strategies, with the same goal of controlling diabetes and achieving cure.
\end{abstract}

Keywords Metabolic surgery $\cdot$ Bariatric surgery $\cdot$ Laparoscopy $\cdot$ Diabetes $\cdot$ Obesity

\section{Introduction}

Morbid obesity is an epidemic disease with a prevalence of $7-10 \%$, predicting to increase to $20 \%$ by 2025 , determining a significant worsening of obesity comorbidities [1]. As a consequence patients with multiple comorbidities including type II diabetes will negatively influence health-care systems and life expectancy $[2,3]$.

Conservative treatments of obesity are not effective on a long-term follow-up. The success rate is even worse in severely obese patients with type 2 diabetes (T2DM) that

Managed by Massimo Federici .

Michela Campanelli

michelacampanelli@live.it

1 Department of Bariatric and Metabolic Surgery, San Carlo of Nancy Hospital, University of Rome Tor Vergata, Rome, Italy

2 Department of Systems Medicine, Chair of Psychiatry, University of Rome Tor Vergata, Rome, Italy

3 Department of Surgery, Policlinico Tor Vergata, Rome, Italy will increase to 439 million by 2030 and to 650 million cases by 2040 [4]. Although the pharmacological approach to treat T2DM has expanded considerably, few patients are able to achieve and maintain optimal glycemic control in the long-term [5]. In the USA, only $52 \%$ of patients with T2DM maintain $\mathrm{HbA} 1 \mathrm{c}<7 \%$ and only $19 \%$ reach this goal with $\mathrm{LDL}<5.6 \mathrm{mmol} / \mathrm{l}$ and blood pressure $<130 / 80 \mathrm{mmHg}$ that are considered parameters to reduce cardiovascular mortality [6].

Bariatric surgery has been proven to determine greater weight loss in morbidly obese patients compared to intensive medical approaches [7-10]. In addition laparoscopic techniques have become safer in recent years $[9,11,12]$. Postoperative complications are rare and long-term results are encouraging [13-16].

Various clinical trials have demonstrated that bariatric procedures induce remission or amelioration of T2DM and other obesity-related comorbidities [9, 10, 13, 17, 18]. Experimental studies and clinical investigations provide scientific evidence that metabolic effects of bariatric surgery are partly independent of weight loss. [19, 20] The knowledge that these operations lead to type II Diabetes remission 
provided a rational to the new concept of metabolic surgery. The aim is therefore to treat metabolic syndrome and type II Diabetes also in patients with mild obesity [21, 22].

For this review article, a selective search (RCT trials, meta-analyses) of two databases (PubMed and the Cochrane Library) between 2000 and 2020 was conducted to investigate the results of metabolic surgery in patients with T2DM and obesity with the aim of highlighting the robust scientific evidence arising from the latest literature works.

\section{Clinical trials}

In the last twenty years, several studies have clearly documented results of bariatric/metabolic surgery on T2DM and associated comorbidities in patients with either BMI $>35 \mathrm{~kg} /$ $\mathrm{m}^{2}$ or $\mathrm{BMI}<35 \mathrm{~kg} / \mathrm{m}^{2}$ [23-25]. In the current literature review, we selected the improvement of type II diabetes as a criteria for the goal of metabolic surgery.

An overall $77 \%$ remission rate in a mean of $14.6 \%$ months of follow-up (range, 6-36) has been reported in 2004 in a meta-analysis of 22,094 diabetic patients by Buchwald et al. [23]. Unfortunately the meta-analysis was based mainly on retrospective studies with short follow-up. A large multicenter prospective study (Swedish Obese Subjects study) [24] compared different bariatric operations with conservative management in groups of well matched obese patients. Seventy-two percent of surgical patient experienced remission of type II diabetes versus $21 \%$ in the medically treated group at two years follow-up. The relative risk (RR) of type II diabetes was three times lower, and the rates of recovery three times greater for surgical patients compared with control group patients after 10 years. In this study, remission was marked by blood glucose $<100 \mathrm{ml} / \mathrm{dl}$, and no diabetes medication needed.

More recently Gill et al. reviewed 27 studies on sleeve gastrectomy with 673 patients and reported a T2DM resolution rate of $66.2 \%$ in obese individuals with improved glycemic control in $26.9 \%$ [25].

Efficacy of bariatric and metabolic surgery has been showed also in several randomized controlled trials (RCT) comparing medical versus surgical management of T2DM. The Diabetes Surgery Study (DSS) randomized trial involved 120 patients to receive intensive lifestyle and medical therapy with or without RYGB [26]. The primary endpoint included achievement of HbA1c $<7.0 \%$, LDL-cholesterol $<100 \mathrm{mg} / \mathrm{dL}$, and systolic blood pressure $<130 \mathrm{mmHg}$. After 12 months, 28 participants in the RYGB group (49\%, 95\% CI 36-63\%) and 11 in the medical management group (19\%, 95\% CI 10-32\%) achieved the primary end points.

The STAMPEDE trial compared medical therapy alone versus medical therapy and Roux-en-Y gastric bypass (RYGB) or Sleeve Gastrectomy (SG) in 150 obese patients
(BMI $27-43 \mathrm{~kg} / \mathrm{m}^{2}$ ) with uncontrolled T2DM. The percentage of patients who reached the primary endpoint (HbA1c of $6.0 \%$ at 1 year) was $12 \%$ in the medical group, $42 \%$ in the RYGB group, and $37 \%$ in the SG group [27]. Also secondary end points, including BMI, body weight, waist circumference, and HOMA-IR were reported to improve after surgery.

Mingrone et al. reported the two years results of RCT in 2012 based on 60 diabetics patients (BMI $>35 \mathrm{~kg} / \mathrm{m}^{2}$ ) of at least 5 years duration with an $\mathrm{HbA} 1 \mathrm{c}$ level of $>7 \%$ comparing traditional medical therapy to RYGB and BPD. No patient in medical therapy group experienced diabetes remission versus 35\% in the RYGB group and $95 \%$ in the BPD group [28]. The Lancet in 2015 published long-term results from this study [29]. Overall, 19 (50\%) of the 38 patients maintained diabetes remission at 5 years compared with none of the 15 patients in the medically treated group ( $p=0.0007)$. Hyperglycemia resolution occurred in 53\% of the patients who achieved 2-year remission in the RYGB group and $37 \%$ of the patients in the BPD group. Weight changes did not predict diabetes that remission is relapse after surgery even if surgical patients lost more weight than the control group.

Until 2020, published literature data about long-term relapse of T2DM after metabolic surgery were limited. No RCTs of metabolic surgery for diabetes were available beyond 5 years of follow-up. In January 2021, Mingrone et al. reported the results of a 10-year follow-up study in the Lancet [30]. It's the same study mentioned above but with a longer-term evaluation of 60 patients with a follow-up rate of $95.0 \%$. Ten-year remission rate were $5.5 \%$ for medical therapy (95\% CI 1.0-25.7), 50.0\% for BPD (29.9-70.1), and $25.0 \%$ for RYGB (11.2-46.9; $p=0.0082)$. All individuals with relapse maintained adequate glycemic control at 10 years. Participants in the surgical groups had fewer diabetes-related complications than those in the medical therapy group. Authors conclude that metabolic surgery is more effective than conventional medical therapy in the long-term control of T2DM. The importance and results of this study should advice clinicians and policy makers to ensure that metabolic surgery is considered in the clinical treatment of patients with obesity and T2DM.

Also for individuals with T2DM and BMI $<35 \mathrm{~kg} / \mathrm{m}^{2}$ clinical studies and RCTs report with a robust evidence that this group of patients may benefits in the disease control from metabolic surgery. A RCT by Dixon et al. in 2008 enrolled individuals with BMI $30-35 \mathrm{~kg} / \mathrm{m}^{2}$ comparing gastric banding with medical treatment [31]. The authors showed at 2-year follow-up remission of T2DM in 73\% in the surgical group and $13 \%$ in the medical therapy group.

In 2012, a prospective study of 66 diabetic patients with BMI $30-35 \mathrm{~kg} / \mathrm{m}^{2}$ who submitted to RYGB showed remission of diabetes in $90 \%$ of them after a follow-up of 6 years [32]. Positive results were also seen in the DSS trial [26] 
including less obese patients with diagnosis of T2DM and follow-up of 12 months. Surgery was associated with greater improvement in $\mathrm{HbA} 1 \mathrm{c}$, LDL-cholesterol, and blood pressure that with medical treatment.

In a recent study, 1016 consecutive patients underwent metabolic surgery with a minimum 1 year follow-up, and the authors reported a significantly higher 1-year total weight loss (30.5\%) and type 2 diabetes mellitus (T2DM) remission (78.4\%) in the OAGB group [33].

Recently, Soong and Colleagues showed long-term outcomes of 134 OAGB patients for the treatment of T2DM with 5 years follow-up. The complete T2DM remission rate of OAGB was $76.1 \%$ at 1 year and $64.2 \%$ at 5 years after surgery, while the T2DM recurrence rate was $15.7 \%$. Finally, forty-one $(57.8 \%)$ out of 71 patients who completed a 10-year follow-up remained in complete T2DM remission [34].

A recent meta-analysis of published studies [35] reporting on diabetes control after bariatric/metabolic surgery considered 94,579 surgical patients. The authors collected all reports appeared in the literature till then. The metaanalysis showed that improvement rates were equivalent in the 60 investigations in which mean baseline BMI of the study cohorts was $>35 \mathrm{~kg} / \mathrm{m}^{2}$ and the 34 studies including patients with mean baseline BMI $<35 \mathrm{~kg} / \mathrm{m}^{2}$ (71\% vs. $72 \%$, respectively).

Another recent meta-analysis and systematic review of RCTs focused on two bariatric procedures, Laparoscopic RYGB and Sleeve Gastrectomy for T2DM in non-severely obese patients with BMI $<35 \mathrm{~kg} / \mathrm{m}^{2}$ [36]. Four RCTs concerning total 296 patients were included. T2DM remission and $\% \mathrm{EWL}$ were similar between the two procedures but both operations improved substantially BMI, waist circumference, LDL, HbA1c, fasting plasma glucose, total cholesterol, and triglyceride.

Considering these outstanding results of metabolic surgery in this group of patients, the indication for the surgical approach to T2DM with mild obesity should be fully considered by clinical Institutions all over the world. Furthermore, surgery in patients with BMI $<35 \mathrm{~kg} /$ $\mathrm{m}^{2}$ should be even safer than bariatric surgery given the less complex clinical features of this group of patients. In Table 1, the results of our literature review concerning mechanisms of action of most popular procedures are summarized. The physiopatologic changes that improve diabetes control after metabolic surgery remain unclear but glucose homeostasis is improved after sleeve gastrectomy (SG), duodenal-jejunal bypass (DJB), Roux-en-Y gastric bypass (RYGB), gastric banding, One Anastomosis Gastric Bypass (OAGB), and biliopancreatic diversion (BPD). Nevertheless, it is also plausible that different gastrointestinal surgeries may have distinct effects and mechanisms of action (Table 2).

\section{A new era}

High quality data from RCTs have clearly established that bariatric procedures are more effective than medical or lifestyle interventions for inducing weight loss and remission of type 2 diabetes, even in mild obese patients with a BMI between 30 and $35 \mathrm{~kg} / \mathrm{m}^{2}$. The second Diabetes Surgery Summit (DSS-II) introduced new guidelines that recommend consideration of metabolic surgery among anti-diabetic interventions for selected patients with obesity and T2DM [37]. As a result, in 2017 DSS-II guidelines were incorporated into the ADA Standards of Diabetes Care [38]. Metabolic surgery, including bariatric procedures previously performed for severe obesity, is now considered as a standard diabetes treatment option for selected individuals with poorly controlled T2DM and BMI $>30 \mathrm{~kg} / \mathrm{m}^{2}$.

The exact physiopatologic mechanism responsible of improved glycemic control after bariatric surgery is unclear although most popular procedures have anatomical and functional difference.

Glucose homeostasis is improved after all types of operation, probably as an expression of weight loss and partial overlap in the mechanism of action. However, given the specific physiological role of the stomach and various intestinal segments in regulating glucose homeostasis, it is also plausible that different gastrointestinal surgeries may have distinct effects and mechanism of action. Although much research has been published and the exact pathway to diabetes improvement remains unidentified, the scientific evidence from RCTs on metabolic surgery for T2DM and obesity is strong, and new guidelines have been proposed (DSS-II) [39].

Metabolic surgery reflex integration of scientific knowledge and multidisciplinary expertise to offer patients a combination of medical and surgical treatment. These are not alternative but complementary with a final goal based on controlling diabetes and achieving cure. 
Table 1 Mechanisms of action of most popular procedures

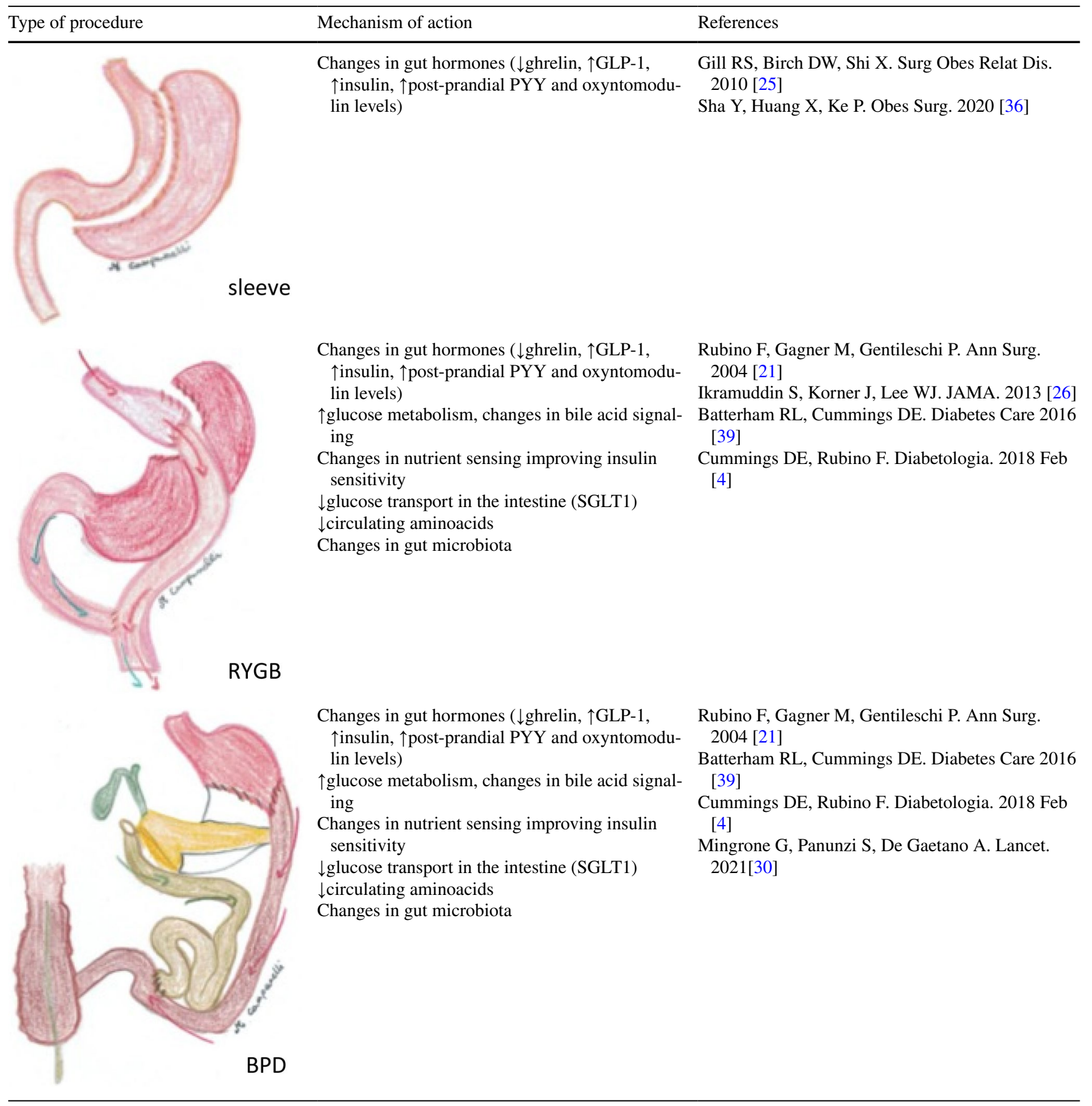

The molecular mechanisms that improve glycemic control after metabolic surgery remain unclear. In spite of anatomical and functional differences between procedures, glucose homeostasis is improved after all these type of procedures. Nevertheless, it is also plausible that different gastrointestinal surgeries may have distinct effects and mechanisms of action 
Table 2 High Quality Clinical trials published in literature between 2004 and 2021

\begin{tabular}{|c|c|c|c|c|}
\hline Authors & $\mathrm{N}^{\circ}$ of cases & Type of surgery & Overall remission rate & Follow-up \\
\hline Buchwald [23] & 22,094 & $\begin{array}{l}\text { Gastric Banding } 47.5 \%(40.7-54.2 \%) \\
\text { Gastric Bypass } 61.6 \%(56.7-66.5 \%) \\
\text { Gastroplasty } 68.2 \%(61.5-74.8 \%) \\
\text { Biliopancreatic Diversion Or Duodenal Switch. } 70.1 \% \\
\quad(66.3-73.9 \%)\end{array}$ & $77 \%$ & 14.6 months (range $6-36$ ) \\
\hline Sjöström [24] & 343 & $\begin{array}{l}\text { Adjustable or non-adjustable banding }(n=61) \text {, } \\
\text { Vertical banded gastroplasty }(n=227), \\
\text { Gastric bypass }(n=55)\end{array}$ & $30.4 \%$ & 10 years \\
\hline Gill [25] & 673 & SG & $66.2 \%$ & 13.1 months (range $3-36$ ) \\
\hline Ikramuddin [26] & 60 & RYGB & $95 \%$ & 12 months \\
\hline Schauer [27] & 97 & RYGB & RYGB $42 \%$ SG $37 \%$ & 3 years \\
\hline Mingrone [28] & 40 & $\begin{array}{l}\text { RYGB } 20 \\
\text { BPD } 20\end{array}$ & $\begin{array}{l}\text { RYGB 75\%; } \\
\text { BPD95\% }\end{array}$ & 2 years \\
\hline Mingrone [29] & 40 & $\begin{array}{l}\text { RYGB } 20 \\
\text { BPD } 20\end{array}$ & RYGB $37 \%$ BPD $63 \%$ & 5 years \\
\hline Mingrone [30] & 40 & $\begin{array}{l}\text { RYGB } 20 \\
\text { BPD } 20\end{array}$ & $\begin{array}{l}\text { BPD 50.0\%; } \\
\text { RYGB } 25.0 \%\end{array}$ & 10 years \\
\hline Dixon [31] & 30 & Laparoscopic gastric banding & $73 \%$ & 2 years \\
\hline Cohen [32] & 66 & RYGB & $88 \%$ & 5 years [range $1-6]$ \\
\hline Panunzi [33] & 4944 & $\begin{array}{l}\text { Laparoscopic gastric banding, RYGB, sleeve Gastrec- } \\
\text { tomy, duodenal-jejunal bypass (DJB), and Biliopancre- } \\
\text { atic diversion (BPD) }\end{array}$ & $\begin{array}{l}\text { PBD } 89 \%, \text { RYGB } 77 \% \text {, } \\
\text { gastric banding } 62 \% \text {, } \\
\text { SG } 60 \%\end{array}$ & $>6$ months \\
\hline Shen [34] & 1016 & $\begin{array}{l}\text { RYGB 197, OAGB 171, SG 437, SG-DJB 130, SA- } \\
\text { DJBSG } 81\end{array}$ & $78.4 \%$ & 1 year \\
\hline Soong [35] & 134 & OAGB & $\begin{array}{l}76.1 \%(1 \text { year }) \\
64.2 \% \text { (5 years) } \\
(57.8 \%) \text { out of } 7110 \text {-year }\end{array}$ & 10 years \\
\hline Sha [36] & 296 & $\begin{array}{l}\text { RYGB } 151 \\
\text { SG } 145\end{array}$ & RYGB $54.0 \%$, SG $56.7 \%$ & 24 to 60 months \\
\hline
\end{tabular}

$S G$ Sleeve Gastrectomy; RYGB Roux-en-Y gastric Bypass; $O A G B$ One Anastomosis Gastric Bypass; $B P D$ Biliopancreatic Diversion; $S G-D J B$ SG with Duodenal-Jejunal Bypass; SA-DJBSG Single Anastomosis Duodenal-Jejunal Bypass with SG

Authors contributions All authors equally contributed to this paper.

Funding Open access funding provided by Università degli Studi di Roma Tor Vergata within the CRUI-CARE Agreement. No foundations are involved in this study.

\section{Declarations}

Conflict of interest All Authors declare no conflict of interest.

Ethical approval All procedures involving human participants were performed in accordance with the ethical standards of the national research committee. This article does not contain studies using animals.

Informed consent This study did not involve human participants so informed consent were not needed.

Open Access This article is licensed under a Creative Commons Attribution 4.0 International License, which permits use, sharing, adaptation, distribution and reproduction in any medium or format, as long as you give appropriate credit to the original author(s) and the source, provide a link to the Creative Commons licence, and indicate if changes were made. The images or other third party material in this article are included in the article's Creative Commons licence, unless indicated otherwise in a credit line to the material. If material is not included in the article's Creative Commons licence and your intended use is not permitted by statutory regulation or exceeds the permitted use, you will need to obtain permission directly from the copyright holder. To view a copy of this licence, visit http://creativecommons.org/licenses/by/4.0/.

\section{References}

1. World Health Organization, Global Health Observatory (GHO) data (2008) Obesity, situation and trends. http://www.who.int/gho/ ncd/risk_factors/overweight/en

2. Bianciardi E, Fabbricatore M, Di Lorenzo G et al (2019) Prevalence of food addiction and Binge eating in an Italian sample of bariatric surgery candidates and overweight/obese patients seeking low-energy-diet therapy. Riv Psichiatr 54(3):127-130. https:// doi.org/10.1708/3181.31602 (PMID: 31282493)

3. Bianciardi E, Gentileschi P, Niolu C et al (2020) Assessing psychopathology in bariatric surgery candidates: discriminant validity of the SCL-90-R and SCL-K-9 in a large sample of patients. 
Eat Weight Disord. https://doi.org/10.1007/s40519-020-01068-2 (Epub ahead of print. PMID: 33226607)

4. Cummings DE, Rubino F (2018) Metabolic surgery for the treatment of type 2 diabetes in obese individuals. Diabetologia 61(2):257-264. https://doi.org/10.1007/s00125-017-4513-y (Epub 2017 Dec 9. PMID: 29224190; PMCID: PMC6448954)

5. Leblanc ES, Oconnor E, Whitlock EP, Patnode CD, Kapka T (2011) Effectiveness of primary care-relevant treatments for obesity in adults: a systematic evidence review for the U.S. preventive services task force. Ann Intern Med 155(7):434-447. https:// doi.org/10.7326/0003-4819-155-7-201110040-00006 (PMID: 21969342)

6. Ali MK, Bullard KM, Saaddine JB, Cowie CC, Imperatore G, Gregg EW (2013) Achievement of goals in U.S. diabetes care, 1999-2010. N Engl J Med. Apr 25; 368(17): 1613-24. Doi: https://doi.org/10.1056/NEJMsa1213829. Erratum in: N Engl J Med. 2013 Aug 8; 369(6): 587. PMID: 23614587

7. Petrescu O, Fan X, Gentileschi P et al (2005) Long-chain fatty acid uptake is upregulated in omental adipocytes from patients undergoing bariatric surgery for obesity. Int J Obes (Lond) 29(2):196203. https://doi.org/10.1038/sj.ijo.0802868 (PMID: 15570311)

8. Bellia A, Marinoni G, D'Adamo M et al (2012) Parathyroid hormone and insulin resistance in distinct phenotypes of severe obesity: a cross-sectional analysis in middle-aged men and premenopausal women. J Clin Endocrinol Metab 97(12):4724-4732. https://doi.org/10.1210/jc.2012-2513 (Epub 2012 Oct 1 PMID: 23027922)

9. Perrone F, Bianciardi E, Ippoliti S et al (2017) Long-term effects of laparoscopic sleeve gastrectomy versus Roux-en-Y gastric bypass for the treatment of morbid obesity: a monocentric prospective study with minimum follow-up of 5 years. Updates Surg 69(1):101-107. https://doi.org/10.1007/s13304-017-0426-Z (Epub 2017 Mar 6 PMID: 28266000)

10. Lombardo M, Bellia A, Mattiuzzo F et al (2015) Frequent followup visits reduce weight regain in long-term management after bariatric surgery. Bariatr Surg Pract Patient Care. https://doi.org/ 10.1089/bari.2015.0021

11. Gentileschi P, Di Paola M, Catarci M et al (2004) Bile duct injuries during laparoscopic cholecystectomy: a 1994-2001 audit on 13,718 operations in the area of Rome. Surg Endosc 18(2):232236. https://doi.org/10.1007/s00464-003-8815-4 (Epub 2003 Dec 29 PMID: 14691705)

12. Gentileschi P, Kini S, Gagner M (2002) Palliative laparoscopic hepatico- and gastrojejunostomy for advanced pancreatic cancer. JSLS 6(4):331-338 (PMID: 12500832; PMCID: PMC3043447)

13. Sjöström L, Lindroos AK, Peltonen M et al (2004) Swedish obese subjects study scientific group lifestyle, diabetes, and cardiovascular risk factors 10 years after bariatric surgery. N Engl J Med 351(26):2683-2693. https://doi.org/10.1056/NEJMoa035622 (PMID: 15616203)

14. Candi E, Tesauro M, Cardillo C et al (2018) Metabolic profiling of visceral adipose tissue from obese subjects with or without metabolic syndrome. Biochem J 475(5):1019-1035. https://doi. org/10.1042/BCJ20170604 (PMID: 29437994)

15. Gentileschi P (2012) Laparoscopic sleeve gastrectomy as a primary operation for morbid obesity: experience with 200 patients. Gastroenterol Res Pract 2012:801325. https://doi.org/10.1155/ 2012/801325 (Epub 2012 Jun 3. PMID: 22701478; PMCID: PMC3371683)

16. Tognoni V, Benavoli D, Bianciardi E et al (2016) Laparoscopic sleeve gastrectomy versus laparoscopic banded sleeve gastrectomy: first prospective pilot randomized study. Gastroenterol Res Pract 2016:6419603. https://doi.org/10.1155/2016/6419603 (Epub 2016 Apr 10. PMID: 27143964; PMCID: PMC4842065)

17. Gentileschi P, Kini S, Catarci M, Gagner M (2002) Evidencebased medicine: open and laparoscopic bariatric surgery. Surg
Endosc 16(5):736-744. https://doi.org/10.1007/s00464-001-8239y (Epub 2002 Jan 4 PMID: 11997813)

18. Bianciardi E, Di Lorenzo G, Niolu C et al (2019) Body image dissatisfaction in individuals with obesity seeking bariatric surgery: exploring the burden of new mediating factors. Riv Psichiatr. 54(1):8-17. https://doi.org/10.1708/3104.30935 (PMID: 30760932)

19. Bianciardi E, Orsaria P, Niolu C, Siracusano A, Gentileschi P (2020) Laparoscopic sleeve gastrectomy for morbid obesity and Klinefelter syndrome: clinical report on two patients, with long-term follow-up. Eat Weight Disord. https://doi.org/10.1007/ s40519-020-00951-2 (Epub ahead of print. PMID: 32654003)

20. Bianciardi E, Imperatori C, Niolu C et al (2020) Bariatric surgery closure during COVID-19 lockdown in Italy: the perspective of waiting list candidates. Front Public Health 17(8):582699. https:// doi.org/10.3389/fpubh.2020.582699 (PMID:33313038;PMCID: PMC7706656)

21. Rubino F, Gagner M, Gentileschi P et al (2004) The early effect of the Roux-en-Y gastric bypass on hormones involved in body weight regulation and glucose metabolism. Ann Surg 240(2):236242. https://doi.org/10.1097/01.sla.0000133117.12646.48 (PMID :15273546;PMCID:PMC1356398)

22. Gaspari AL, Di Lorenzo N, Gentileschi P, Camperchioli I (2009) La chirurgia metabolica [Metabolic surgery]. G Chir. 30(4):133140 (Italian. PMID: 19419612)

23. Buchwald H, Avidor Y, Braunwald E, Jensen MD, Pories W, Fahrbach K, Schoelles K (2005) Bariatric surgery: a systematic review and meta-analysis. JAMA. 2004 292(14):1724-37. Doi: https:// doi.org/10.1001/jama.292.14.1724. Erratum in: JAMA. Apr 13; 293(14):1728. PMID: 15479938

24. Sjöström L, Peltonen M, Jacobson P et al (2014) Association of bariatric surgery with long-term remission of type 2 diabetes and with microvascular and macrovascular complications. JAMA 311(22):2297-2304. https://doi.org/10.1001/jama.2014.5988 (PMID: 24915261)

25. Gill RS, Birch DW, Shi X, Sharma AM, Karmali S (2010) Sleeve gastrectomy and type 2 diabetes mellitus: a systematic review. Surg Obes Relat Dis. 6(6):707-713. https://doi.org/10.1016/j. soard.2010.07.011 (Epub 2010 Aug 6 PMID: 20947447)

26. Ikramuddin S, Korner J, Lee WJ et al (2013) Roux-en-Y gastric bypass vs intensive medical management for the control of type 2 diabetes, hypertension, and hyperlipidemia: the diabetes surgery study randomized clinical trial. JAMA 309(21):2240-2249. https://doi.org/10.1001/jama.2013.5835 (PMID:23736733;PMC ID:PMC3954742)

27. Schauer PR, Bhatt DL, Kirwan JP et al (2014) STAMPEDE Investigators. Bariatric surgery versus intensive medical therapy for diabetes-3-year outcomes. N Engl J Med 370(21):2002-2013. https://doi.org/10.1056/NEJMoa1401329 (Epub 2014 Mar 31. PMID: 24679060; PMCID: PMC5451259)

28. Mingrone G, Panunzi S, De Gaetano A et al (2012) Bariatric surgery versus conventional medical therapy for type 2 diabetes. $\mathrm{N}$ Engl J Med 366(17):1577-1585. https://doi.org/10.1056/NEJMo a1200111 (Epub 2012 Mar 26 PMID: 22449317)

29. Mingrone G, Panunzi S, De Gaetano A (2015) Bariatric-metabolic surgery versus conventional medical treatment in obese patients with type 2 diabetes: 5 year follow-up of an open-label, singlecentre, randomised controlled trial. Lancet 386(9997):964-973. https://doi.org/10.1016/S0140-6736(15)00075-6 (PMID: 26369473)

30. Mingrone G, Panunzi S, De Gaetano A et al (2021) Metabolic surgery versus conventional medical therapy in patients with type 2 diabetes: 10-year follow-up of an open-label, single-centre, randomised controlled trial. Lancet 397(10271):293-304. https://doi. org/10.1016/S0140-6736(20)32649-0 (PMID: 33485454) 
31. Dixon JB, O'Brien PE, Playfair J et al (2008) Adjustable gastric banding and conventional therapy for type 2 diabetes: a randomized controlled trial. JAMA 299(3):316-323. https://doi.org/ 10.1001/jama.299.3.316 (PMID: 18212316)

32. Cohen RV, Pinheiro JC, Schiavon CA, Salles JE, Wajchenberg BL, Cummings DE (2012) Effects of gastric bypass surgery in patients with type 2 diabetes and only mild obesity. Diabetes Care 35(7):1420-1428. https://doi.org/10.2337/dc11-2289.PMID: 22723580;PMCID:PMC3379595

33. Panunzi S, De Gaetano A, Carnicelli A, Mingrone G (2015) Predictors of remission of diabetes mellitus in severely obese individuals undergoing bariatric surgery: do BMI or procedure choice matter? A meta-analysis. Ann Surg 261(3):459-467. https://doi. org/10.1097/SLA.0000000000000863 (PMID: 25361217)

34. Shen SC, Lee WJ, Kasama K et al (2021) Efficacy of different procedures of metabolic surgery for type 2 diabetes in Asia: a multinational and multicenter exploratory study. Obes Surg. https://doi. org/10.1007/s11695-021-05239-7 (Epub ahead of print. PMID: 33523416)

35. Soong TC, Lee MH, Lee WJ, Chen JC, Wu CC, Chun SC (2021) One Anastomosis gastric bypass for the treatment of type 2 diabetes: long-term results and recurrence. Obes Surg 31(3):935-941. https://doi.org/10.1007/s11695-020-05093-z (Epub 2020 Nov 3 PMID: 33145718)
36. Sha Y, Huang X, Ke P, Wang B, Yuan H, Yuan W, Wang Y, Zhu $X$, Yan Y (2020) Laparoscopic Roux-en-Y gastric bypass versus sleeve gastrectomy for type 2 diabetes mellitus in nonseverely obese patients: a systematic review and meta-analysis of randomized controlled trials. Obes Surg 30(5):1660-1670. https://doi. org/10.1007/s11695-019-04378-2 (PMID: 31912466)

37. Rubino F, Nathan DM, Eckel RH et al (2016) Delegates of the 2nd diabetes surgery summit metabolic surgery in the treatment algorithm for type 2 diabetes: a joint statement by international diabetes organizations. Diabetes Care 39(6):861-877. https://doi. org/10.2337/dc16-0236 (PMID: 27222544)

38. American Diabetes Association (2017) 7. Obesity management for the treatment of type 2 diabetes. Diabetes Care 40(Suppl 1):S57S63. https://doi.org/10.2337/dc17-S010 (PMID: 27979894)

39. Batterham RL, Cummings DE (2016) Mechanisms of diabetes improvement following bariatric/metabolic surgery. Diabetes Care 39:893-901

Publisher's Note Springer Nature remains neutral with regard to jurisdictional claims in published maps and institutional affiliations. 